\title{
BipaddlePectoralis Major Myocutaneous Flap for oral cancer reconstruction: Operative technique, flap reliability and outcome, Asingle Institute experience.
}

\author{
Dr. Navneet Jain, ${ }^{1}$. Dr.Birinder Pal Singh ${ }^{2}$ Dr.Sunilsaini M.S ${ }^{3}$.(General surgery) \\ ${ }^{I}$ Assistant Professor Cancer Research Institute Swami Rama Himalayan University Jollygrant P.O. Doiwala \\ Dehradun - 248140 (UK) \\ ${ }^{2}$ MS(General Surgery), Fellowship Surgical Oncology Cancer Research Institute, SRHU, Dehradun. \\ ${ }^{3}$ Professor,Cancer Research Institute Swami Rama Himalayan University Dehradun
}

\begin{abstract}
Purpose: The Bipaddle pectoralis major myocutaneous flap (PMMF) is a commonly used flap in reconstructive head and neck surgery in advanced cases, but in literature, the flap is also associated with a high incidence of complications in addition to its large bulk. The purpose of the study is the evaluation of the flap reliability, operative technique and outcome in reconstructive head and neck cancer surgery.

Patients and methods:

The records of all patients treated with a bippadle PMMF between 2012 and 2015 were systematically reviewed. Data of recipient localization, main indication, operative technique, postoperative complications and outcomes were analyzed. Major complications were evaluated if revision surgery was necessary and minor ones if conservative wound care alone was required.

Results: The male to female ratio was 4.6:1, with a mean age of 51 years (45-64). PMMF reconstruction was done in all patients of advanced squamous cell carcinoma of oral cavity. In 3 female patients (10.7\%), minor flap related complications were seen, however recovered well with acceptable final outcome.

Conclusion: The Bipaddle PMMF is reliable for large defects in head and neck reconstructive surgery, particularly when a bulky flap is needed and the lesion is involving the outer skin. Placing the flap horizontally with inclusion of nipple and areola in most of the patients increased the reach and size of available flap.
\end{abstract}

Keywords: Full thickness cheek and oral defects, operative technique, Bipaddle pectoralis major myocutaneous flap (PMMF).

\section{Introduction}

Since the time of Aryan's description in 1979, the use of pectoralis major myocutaneous flap is rediscovered and has been used as the workhorse for head and neck reconstruction. Reconstruction of defect created after excision of advanced head and neck malignancies is still a challenge to reconstructive surgeons. These complex excisional defects often have extensive loss of mucosa, bone, soft tissue and skin. Ideal reconstruction should replace all these diseased structures to achieve acceptable aesthetic and functional results. Primary reconstruction of such defects with microsurgical techniques is now the protocol in almost all major cancer centers $[1,2]$. But in view of the long operative time, specific and costly materials, the need for expertise and infrastructure and the large work volume in developing countries offering microsurgical reconstruction to all patients with such defects is not possible. Another factor limiting the use of free flaps is the necessity of good-quality recipient blood vessels for microvascular anastomosis [3]. Therefore using PMMC flap alone for lining as well as cover is also an established procedure now [4].

Complications from PMMF vary widely in the literature, where reported rates range from 13\% to $63 \%$ [5], and several risk factors are described for complications and failures when this flap is employed. Some authors assertion that, in skilled hands, free flaps result in fewer complications than do PMMFs $[6,7]$ there is a consensus that total flap necrosis is a rare complication when PMMFs are used, even when an inexperienced surgeon harvests the flap [8-12]. In addition, some of the complications associated with PMMF like mild skin flap necrosis can be managed by conservative approach with satisfactory results [12-15]. The disadvantages of pedicle flap can include a reduced neck mobility and the need to rotate the vascular pedicle of the flap $180^{\circ}$ when using the skin paddle. Another disadvantage can be the thickness of the flap, which is determined by the amount of subcutaneous fat between thepectoralis muscle and the overlying skin paddle, leading to possible reduced swallowing or speech functions.

\section{Objective}


The objective of this study was to analyze our experience with Bippadle PMMFs for head and neck reconstruction in advanced cases for the flap reliability, operative technique, complications and outcomes when this flap is employed.

\section{Metarial And Method}

Total 28 cases were studied that underwent radical composite resection and reconstructed usingBipaddle PMMFs between 2012 and 2015 at Cancer Research Institute, Swami Rama Himalayan University, Dehradun, India were systematically reviewed. The tumors were staged in accordance with the TNM criteria (AJCC)[38]. as stages I to IV. All Patients were eligible for the study if they had presented with advanced malignant tumors of the buccal mucosa involving the bone(mandible) and the skin of the face. Patients underwent immediate reconstruction using Bipaddle PMMFs. Data of recipient localization, main indication, and postoperative complications were analyzed. The complications were classified as flap-related complicationsif they were directly associated with the flap, the repaired area or the donor site. The flap-related complications were categorized s as majorcomplicationsor minor complications. Major complications were those that required reoperation in a surgical theater, or resulted in failure to attain the reconstruction goal. Minor complications were those that were treated successfully by means of conservative management with successful reconstruction. Conservative management in cluded packing, small drainage, debridement and medication. When one complication gave rise to another, only the final complication was taken into consideration, in an attempt to represent the overall outcome from a succession of complications in an individual patient. For example, if dehiscence resulted in orocutaneous fistula, then the fistula was considered to be the complication. Among the cases that developed some kind of flap necrosis, we tried to identify possible technical causes that could be correlated with this. Unrelated complications were considered separately [15-25].

\section{Flap design and operative technique:}

The various surgical techniques used to harvest the PMMF was described in the literature $[8,9,26,27]$ and the vascular pedicle was dissected under direct viewing. First, the clavicle, xiphoid, ipsilateral sternal border are identified, and then the size and location of the skin paddle being located at the inferior-medial border of the pectoralis major muscle are marked. The vascular axis is drawn on the skin of the chest. Second, the initial incision is made at the lateral part toward the anterior axillary line down to the pectoralis major muscle. The maximum amount of muscle should be harvested, because the larger the muscle volume, the safer the flap due to the increased number of myocutaneous perforators. Third, the inferior, medial and lateral incisions are made through the skin, subcutaneous fat and pectoralis fascia down to the chest wall. The superior incision is made down to the muscle fibres and the skin island is tightened to the muscle with absorbable sutures to protect the skin island during operative handling.

As the muscle is elevated inferiorly to superiorly, the pedicle should be identified by palpation and visualization on the deep surface of the muscle. The pectoralis major muscle derives its blood supply from the pectoral branch of the thoracoacromial artery and lateral thoracic artery. The thoracoacromial artery descends from its origin from the subclavian artery at the level of themidclavicular point in an inferomedial direction and anastomoses within the muscle with the direct branches of internal mammary and anterior intercostals branches of the internal mammary artery. The perforating branches to the skin paddle area used for head and neck reconstruction are located in 3 distinct places. First: along the medial edge of the muscle, directmusculocutaneous branches from the internal mammary artery.Second: 2-4 cm medial to the nipple, coming from the anterior intercostal branch of internal mammary artery. Third: fine branches reaching the skin by curving around the lateral border of the muscle.Because of the rich anastomotic network within the muscle, blood supply from thoracoacromial artery safely reaches the skin even after ligation of the branches of the internal mammary and lateral thoracic artery [26-28].

When the muscle fibres are cut along the sternal attachment, special attention should be taken not to cut the internal mammary perforators adjacent to the sternum that supply the deltopectoral flap. During the dissection the vascular bundle should always be seen in order to avoid injury to this bundle. After dissection the flap off the chest wall, a subcutaneous tunnel is formed under the skin between neck (preserving the perforators to the overlying deltopectoral flap) and the chest and the flap is passed underneath the skin bridge. In all of the cases, the supraclavicular route was used to transfer the flap to the defect. Magrim et al. use sterile liquid vaseline to lubricate the bulky flap and to raise the ipsilateral shoulder in order to facilitate passage and during the procedure, to instill a vasodilator substance (papaverine or lidocaine) over the flap pedicle [29]. The paddle was placed horizontally, including the nipple and areola, which extends from midline medially and crossing the lateral border of the muscle laterally increases the reach and size of available flap. Figure 1a\&b showing Primary Lesion and Size of Bipaddle . Paddle for lining defect was placed around the nipple, that paddle was nourished by two sets of perforators (P2, P3). The paddle for the skin defect was placed on the medial edge of the muscle based on P1 perforators. The paddle was placed along the transverse axis, so that the reach of flap 
was not compromised (Figure 2). If the nipple is prominent then it was excised and closed with a stitch and even spared in some patients. The technique was found to be anatomically sound, technically easy and reliable. Precautions that were taken included proper assessment of reach of the paddle, placing not more than one-third of the paddle outside the muscle and securing the skin paddle to the muscle to avoid shearing of perforators during flap raising. However, the disadvantages of bipaddle flap include loss of nipple and areola in most patients and technical difficulty in obese patients and females. Another pitfall, relates to the lateral pectoralis nerve division. It is observed that this nerve may lie parallel or oblique to the PMMF vascular pedicle. When running obliquely to the pedicle, the lateral thoracic nerve becomes taut after the flap is rotated through $180^{\circ}$ and presses against the vascular pedicle, thus leading to PMMF vascular impairment. This phenomenon is seen in $30 \%$ of their cases and recommended that this nerve should be dissected and divided when the above situation is observed [30]. In regard to the possible arc of the rotation of the flap, soft tissue defects anterior to the retromolar region and inferior to the ear lobe and commissure of the lips can be reconstructed with relative ease [31]. Primary closure of the chest donor site was done inspite of large size of the skin paddle, due to the wide undermining of skin flaps. Most authors performed a primary closure but in some cases, different techniques have been described like buttons or Ventrofil@, a special tension- relief bridging device [32]. Closed suction drains are used to drain the donor site as well as the neck.

\section{Results}

Total 28 cases were studied. Among these, 25 (89.2\%) were men. The age of patients ranged from 45 to 64 years (mean 52.3 years). All patients were reconstructed primarily by bipaddle pectoralis major myocutaneous (PMMC) flap. All the tumors were operable squamous cell carcinomas, mainly located in the oral cavity and cheek, and most of these were at an advanced stage of disease (stages III and IV) (Table 1).

Table1. Disease stage $(n=28)$

\begin{tabular}{|l|l|l|}
\hline Disease stage & Number of cases & $\begin{array}{l}\text { Percentage } \\
(\%)\end{array}$ \\
\hline IV & 21 & $75 \%$ \\
\hline III & 7 & $25 \%$ \\
\hline II & 0 & $0 \%$ \\
\hline I & 0 & $0 \%$ \\
\hline
\end{tabular}

All patients underwent composite resection (wide excision of the primary tumour with segmental/hemi/totalmandibulectomy and neck dissection in continuity). Neck dissections in all cases were modified type in twenty four and radical in four patients and sternocleidomastoid muscle was removed in all. This provides us a space to accommodate the PMMC flap muscle in neck. All patients received postoperative radiation therapy. The size of the paddle used for mucosal defect repair ranged from $4 \times 4$ to $8 \times 7 \mathrm{~cm}$ and the size of the paddle used for skin cover ranged from $4 \times 4$ to $8 \times 8 \mathrm{~cm}$. The total flap size ranged from $9 \times 4$ to $15 \times 7 \mathrm{~cm}$ (Table 2). All patients achieved satisfactory cover. Besides partial or complete necrosis, other complications such as fistula formation, dehiscence, infection, and hematoma are described [23, 33]. The complication rate seems to be higher than in free flap reconstructions as, e.g., radial forearm flap [33]. Several reasons for complications have been described. McLean et al [22] reported complications mainly in patients after radiotherapy. A higher complication rate seems to be associated with the use of the flap as a salvage procedure and the presence of more than one risk factor by some for example if the patient is a heavy smoker and or the procedure is oral cavity reconstruction [17], while others reported no significantly higher complication rate associated with smoking, preoperative radiotherapy, or diabetes [21, 24].

Table 2.Particulars of the patients in present study.

\begin{tabular}{|l|l|l|l|l|l|l|l|}
\hline S.N. & Age & Sex & Complications & \multicolumn{2}{l|}{ Paddle size $(\mathrm{cm})$} & Hospital Stay (Days) \\
\hline & & & & Lining & Cover & Total & \\
\hline 1 & 56 & M & Nil & $6 \times 6$ & $7 \times 6$ & $13 \times 6$ & 12 \\
\hline 2 & 63 & M & Nil & $7 \times 7$ & $6 \times 6$ & $13 \times 6$ & 10 \\
\hline 3 & 48 & M & Nil & $6 \times 8$ & $6 \times 6$ & $14 \times 6$ & 8 \\
\hline 4 & 50 & M & $\begin{array}{l}\text { Salivary } \\
\text { Collection }\end{array}$ & $6 \times 5$ & $6 \times 5$ & $12 \times 5$ & 14 \\
\hline 5 & 47 & M & Nil & $7 \times 7$ & $6 \times 7$ & $14 \times 7$ & 9 \\
\hline 6 & 45 & F & $\begin{array}{l}\text { Partial Flap } \\
\text { Necrosis }\end{array}$ & $5 \times 5$ & $6 \times 5$ & $11 \times 5$ & 35 \\
\hline 7 & 55 & M & Nil & $7 \times 7$ & $8 \times 8$ & $15 \times 7$ & 10 \\
\hline 8 & 59 & M & Nil & $7 \times 6$ & $5 \times 6$ & $12 \times 6$ & 9 \\
\hline 9 & 50 & F & $\begin{array}{l}\text { Partial Nlap } \\
\text { Necrosis }\end{array}$ & $6 \times 8$ & $7 \times 6$ & $15 \times 6$ & 20 \\
\hline 10 & 64 & M & Nil & $5 \times 6$ & $4 \times 4$ & $10 \times 5$ & 8 \\
\hline 11 & 46 & M & Orocutaneous & $6 \times 6$ & $5 \times 5$ & $11 \times 6$ & 16 \\
\hline
\end{tabular}


BipaddlePectoralis Major Myocutaneous Flap for oral cancer reconstruction: Operative technique

\begin{tabular}{|l|l|l|l|l|l|l|l|}
\hline & & & fistula & & & & \\
\hline 12 & 45 & M & Nil & $6 \times 7$ & $6 \times 5$ & $13 \times 6$ & 9 \\
\hline 13 & 54 & M & Nil & $5 \times 4$ & $4 \times 4$ & $9 \times 4$ & 7 \\
\hline 14 & 49 & M & $\begin{array}{l}\text { Minor Wound } \\
\text { Dehisence }\end{array}$ & $8 \times 7$ & $7 \times 7$ & $15 \times 7$ & 14 \\
\hline 15 & 46 & M & Nil & $7 \times 5$ & $6 \times 5$ & $13 \times 5$ & 8 \\
\hline 16 & 51 & M & Nil & $6 \times 6$ & $5 \times 5$ & $11 \times 6$ & 9 \\
\hline 17 & 58 & M & Nil & $4 \times 4$ & $6 \times 7$ & $11 \times 5$ & 12 \\
\hline 18 & 47 & M & Nil & $7 \times 6$ & $6 \times 6$ & $13 \times 6$ & 10 \\
\hline 19 & 54 & M & Nil & $5 \times 6$ & $6 \times 6$ & $11 \times 6$ & 8 \\
\hline 20 & 62 & M & Nil & $5 \times 5$ & $6 \times 5$ & $11 \times 5$ & 7 \\
\hline 21 & 46 & M & $\begin{array}{l}\text { Salivary } \\
\text { Collection }\end{array}$ & $6 \times 6$ & $7 \times 6$ & $13 \times 6$ & 16 \\
\hline 22 & 56 & F & Nil & $7 \times 7$ & $8 \times 8$ & $15 \times 7$ & 9 \\
\hline 23 & 48 & M & Nil & $5 \times 4$ & $4 \times 4$ & $9 \times 4$ & 10 \\
\hline 24 & 52 & M & $\begin{array}{l}\text { Partial } \\
\text { Necrosis }\end{array}$ & $8 \times 6$ & $7 \times 6$ & $15 \times 6$ & 19 \\
\hline 25 & 59 & M & Nil & $6 \times 8$ & $6 \times 6$ & $14 \times 6$ & 7 \\
\hline 26 & 60 & M & Nil & $6 \times 7$ & $6 \times 6$ & $12 \times 7$ & 8 \\
\hline 27 & 49 & M & Nil & $7 \times 7$ & $8 \times 8$ & $15 \times 7$ & 15 \\
\hline 28 & 47 & M & $\begin{array}{l}\text { Partial } \\
\text { Necrosis }\end{array}$ & & & & \\
\hline
\end{tabular}

Table 3. Flap-related major and minor complications $(\mathrm{n}=28)$

\begin{tabular}{|c|c|c|}
\hline Major complications & Number of cases & $\%$ \\
\hline No & 23 & $82.14 \%$ \\
\hline Yes & 5 & $17.85 \%$ \\
\hline $\begin{array}{l}\text { Partial flap loss } \\
+ \text { intraoral flap dehiscence }\end{array}$ & 4 & $14.28 \%$ \\
\hline Orocutaneous fistula & 1 & $3.57 \%$ \\
\hline Minor complications & Number of cases & $\%$ \\
\hline No & 25 & $89.28 \%$ \\
\hline Yes & 3 & $10.71 \%$ \\
\hline Neck skin dehiscence & 1 & $3.57 \%$ \\
\hline Salivary collection & 2 & $7.14 \%$ \\
\hline
\end{tabular}

Four patients had skin necrosis of outer flaps, one had wound infection with resultant orocutaneous fistula, two patients had salivary collection and one case had skin wound dehiscence (Table 3). For skin necrosis, one was reconstructed with local advancement flap and three covered with split skin graft. Orocutaneous fistula responded to local wound care. Minor wound dehiscence required debridement and resuturing, and both minor salivary collection between the two paddles of flap responded to repeated aspiration. Reconstruction time was approximately $3 \mathrm{~h}$ (range 2 to 4: $00 \mathrm{~h}$ ). The mean duration of hospital stay was 12 days (range 7-35 days). All patients finally achieved acceptable functional and cosmetic results except one female patient (Figure 3a,). The intraoperative and the immediate postoperative course in all patients remained uneventful. Three patients received preoperative radiotherapy and all the other patients required postoperative radiation therapy. The postoperative radiotherapy was tolerated well. On follow up, the flaps proved to be robust as well.Fig. $3 b$ and $4(a, b)$.

\section{Discussion}

Easy reach of the flap uptoretromolar region and cheek, good vascularity based on perforators, technical simplicity, coverage of the exposed vessels by muscle after neck dissection and the ability to provide bulk in the neck made it a popular option amongst oncoreconstructive surgeons. A good success rate for reconstruction purposes was observed using PMMFs $(82.14 \%)$, and this rate compares favorably with several papers in the literature $[8,17,21,24,34,35]$. The present study did not observe any cases of total flap loss and rate of partial loss was acceptable, with good final outcome observed in four such cases.

These results are also comparable to those in the literature. In females the use of an inframammary incision is recommended for aesthetic reasons positioning the skin island just medially to the nipple, over the fourth, fifth and sixth intercostal spaces, is essential for encompassing the skin perforator vessels that arise from the intercostal branches of the internal thoracic artery. These cutaneous vessels are supplied by the pectoralis branch of the thoracoacromial artery, through open choke vessels, when the main blood flow through the internal thoracic artery is interrupted during PMMF elevation. Hence, a totally axial myocutaneous flap may be created respecting this anatomical condition. Below the seventh rib, the vascular supply for the skin comes from the cutaneous branches of the superior epigastric artery,[36]] and therefore, when portions of skin beyond this limit are included in the flap, this creates an axial flap with a distal random portion, thereby increasing the risk 
of partial loss. In females there is intervening extra fatty tissue in breasts as compared to males. In these two female patients, the skin island extended below the seventh rib and the skin paddle was small in one patientthat probably did not encompass a sufficient number of skin perforator vessels, thus resulting in unstable blood circulation [37]. Almost fifty percent reduction in bulkiness of flap is reported within three months due to its atrophy after division of the motor nerves [19]. Proper flap design and operative technique should be implied for bipaddling in females and obese patients due to unreliability of skin paddle over the breast tissue and a very bulky flap. . The bone replacement was not possible, in lateral and posterior mandibulectomies it was not always necessary to replace the bone since the soft tissue can provide acceptable aesthesis and prevent jaw deviation to some extent.

\section{Conclusion}

Since the risk factors for developing major complications and outcome failure may be anticipated, we are convinced that if the technical pitfalls listed throughout this study are given due attention and judicious clinical and nutritional support is provided for patients in a . more critical condition, better results can be obtained.Bipaddle PMMF is a reliable and robust reconstructive option even in female patients.

\section{References}

[1]. Koshima I, Yamamoto H, Hosoda M, Moriguchi T, Nagayama H. Free combined composite flaps using the lateral circumflex femoral system for repair of massive defects of head and neck region: an introduction to the chimeric flap principle. PlastReconstrSurg 1993;92:411-20.

[2]. Demikran F, Dheu HC, Wie FC, Chen HH, Jung SG, Hau SP, et al. The versatile anterolateral thigh flap: a musculocutaneous flap in disguise in head and neck reconstruction. Br J PlastSurg 2000;53:30-6.

[3]. Bhathena HM, Kavrana NM. The folded, bipaddledpectoralis major composite flap in oral reconstruction. Br $\mathrm{J}$ PlastSurg 1989;42:441-6.

[4]. C.-Y. Hsing, Y.-K.Wong, C. P. Wang et al., "Comparison between free flap and pectoralis major pedicled flap for reconstruction in oral cavity cancer patients - a quality of life analysis," Oral Oncology, vol. 47, no. 6, pp. 522-527, 2011.

[5]. A. L. Kruse, H. T. Luebbers, J. A. Obwegeser, M. Bredell, and K. W. Gratz, "Evaluation of the pectoralis major flap for reconstructive head and neck surgery," Head \& Neck Oncology, vol. 3, p. 12, 2011.

[6]. Chepeha DB, Annich G, Pynnonen MA, et al. Pectoralis major myocutaneous flap vsrevascularized free tissue transfer: complications, gastrostomy tube dependence, and hospitalization. Arch Otolaryngol Head Neck Surg. 2004;130(2):181-6.

[7]. Tsue TT, Desyatnikova SS, Deleyiannis FW, et al. Comparison of cost and function in reconstruction of the posterior oral cavity and oropharynx. Free vspedicled soft tissue transfer. Arch Otolaryngol Head Neck Surg. 1997;123(7):731-7.

[8]. Milenović A, Virag M, Uglesić V, Aljinović-Ratković N. The pectoralis major flap in head and neck reconstruction: first 500 patients. J Craniomaxillofac Surg. 2006;34(6):340-3.

[9]. Ariyan S. Further experiences with the pectoralis major myocutaneous flap for the immediate repair of defects from excisions of head and neck cancers. PlastReconstr Surg. 1979;64(5):605-12.

[10]. Baek SM, Lawson W, Biller HF. An analysis of 133 pectoralis major myocutaneous flaps. PlastReconstr Surg. 1982;69(3):460-9.

[11]. Nagral S, Sankhe M, Patel CV. Experience with the pectoralis major myocutaneous flap for head and neck reconstruction in a general surgical unit. J Postgrad Med. 1992;38(3):119-23.

[12]. Koh KS, Eom JS, Kirk I, Kim SY, Nam S. Pectoralis major musculocutaneous flap in oropharyngeal reconstruction: revisited. PlastReconstr Surg. 2006;118(5):1145-9; discussion 1150.

[13]. Castelli ML, Pecorari G, Succo G, et al. Pectoralis major myocutaneous flap: analysis of complications in difficult patients. Eur Arch Otorhinolaryngol. 2001;258(10):542-5.

[14]. Wadwongtham W, Isipradit P, Supanakorn S. The pectoralis major myocutaneous flap: applications and complications in head and neck reconstruction. J Med Assoc Thai. 2004;87Suppl 2:S95-9.

[15]. Saussez S, Cuno A, Urbain F, Chantrain G, Lequeux T. Reconstruction of circumferential oro- and hypopharyngeal defects with Ushaped pectoralis major myocutaneous flap. Otolaryngol Head Neck Surg. 2006;134(5):823-9.

[16]. Dedivitis RA, Guimaraes AV: Pectoralis major musculocutaneous flap in head and neck cancer reconstruction. World J Surg 2002, 26:67-71.

[17]. El-Marakby HH: The reliability of pectoralis major myocutaneous flap in head and neck reconstruction. J Egypt NatlCancInst 2006, 18:41-50.

[18]. Ethier JL, Trites J, Taylor SM: Pectoralis major myofascial flap in head and neck reconstruction: indications and outcomes. J Otolaryngol Head Neck Surg 2009, 38:632-641.

[19]. IJsselstein CB, Hovius SE, ten Have BL, Wijthoff SJ, Sonneveld GJ, Meeuwis CA, Knegt PP: Is the pectoralismyocutaneous flap in intraoral and oropharyngeal reconstruction outdated? Am J Surg 1996, 172:259-262.

[20]. Kroll SS, Goepfert H, Jones M, Guillamondegui O, Schusterman M: Analysis of complications in 168 pectoralis major myocutaneous flaps used for head and neck reconstruction. Ann PlastSurg 1990, 25:93-97.

[21]. Liu R, Gullane P, Brown D, Irish J: Pectoralis major myocutaneouspedicled flap in head and neck reconstruction: retrospective review of indications and results in 244 consecutive cases at the Toronto General Hospital. J Otolaryngol 2001, 30:34-40.

[22]. McLean JN, Carlson GW, Losken A: The pectoralis major myocutaneous flap revisited: a reliable technique for head and neck reconstruction. Ann PlastSurg 2010, 64:570-573.

[23]. Shah JP, Haribhakti V, Loree TR, Sutaria P: Complications of the pectoralis major myocutaneous flap in head and neck reconstruction. Am J Surg 1990, 160:352-355.

[24]. Vartanian JG, Carvalho AL, Carvalho SM, Mizobe L, Magrin J, Kowalski LP: Pectoralis major and other myofascial/myocutaneous flaps in head and neck cancer reconstruction: experience with 437 cases at a single institution. Head Neck 2004, 26:1018-1023.

[25]. Zbar RI, Funk GF, McCulloch TM, Graham SM, Hoffman HT: Pectoralis major myofascial flap: a valuable tool in contemporary head and neck reconstruction. Head Neck 1997, 19:412-418.

[26]. Ariyan S. The pectoralis major myocutaneous flap. A versatile flap for reconstruction in the head and neck.PlastReconstr Surg. 1979;63(1):73-81. 
[27]. Freeman JL, Walker EP, Wilson JS, Shaw HJ. The vascular anatomy of the pectoralis major myocutaneous flap. Br J Plast Surg. 1981;34(1):3-10.

[28]. Kiyokawa K, Tai Y, Tanabe HY, Inone Y, Yamadi T, Rikimaru H, et al. A method that preserves circulation during preparation of the pectoralis major myocutaneous flap in head and neck reconstruction.PlastReconstrSurg 1998;102:2336-45.

[29]. Magrim J, Filho JG: Practical tips for perfomring a pectoralis major flap. In Pearls and pitfalls in head and neck surgery.Edited by: Cerne CR, Dias FL, Dima RA, Myers EN, Wei WI. Basel: Karger; 2008:180-181.

[30]. Cunha-Gomes D, Choudhari C, Kavarana NM. Vascular compromise of the pectoralis major musculocutaneous flap in head and neck reconstruction. Ann Plast Surg. 2003;51(5):450-4.

[31]. Carlson ER: Pectoralis major myocutaneous flap. Oral MaxillofacSurgClin North Am 2003, 15:565-575, vi.

[32]. Kruse AL, Luebbers HT, Gratz KW, Bredell M: A new method for closure of large donor side defects after raising the pectoralis major flap. Oral MaxillofacSurg 2010.

[33]. Schusterman MA, Kroll SS, Weber RS, Byers RM, Guillamondegui O, Goepfert H: Intraoral soft tissue reconstruction after cancer ablation: a comparison of the pectoralis major flap and the free radial forearm flap. Am J Surg 1991, 162:397-399.

[34]. PfuetzenreiterJúnior EG, Andrade CRA, Lehn CN, Dedivitis RA. O retalhomúsculo-cutâneopeitoralmaiornareconstrução do câncer de cabeça e pescoço [The pectoralis major musculocutaneous flap in head and neck cancer reconstruction]. Arq Bras CiêncSaúde. 2008;33(3):151-4.

[35]. Magrin J, Kowalski LP, Sabóia M, Sabóia RP. Major glossectomy: end results of 106 cases. Eur J Cancer B Oral Oncol. $1996 ; 32 \mathrm{~B}(6): 407-12$.

[36]. Rikimaru H, Kiyokawa K, Inoue Y, Tai Y. Three-dimensional anatomical vascular distribution in the pectoralis major myocutaneous flap. PlastReconstr Surg. 2005;115(5):1342-52; discussion 1353-4.

[37]. Rikimaru H, Kiyokawa K, Watanabe K, et al. New method of preparing a pectoralis major myocutaneous flap with a skin paddle that includes the third intercostal perforating branch of the internal thoracic artery. PlastReconstr Surg. 2009;123(4):1220-8.

[38]. EdgeSB,ByrdDR,ComptonCC,eds.AJCC Cancer Staging Handbook.7th ed.New York: Springer;2010

\section{Figure legands:}

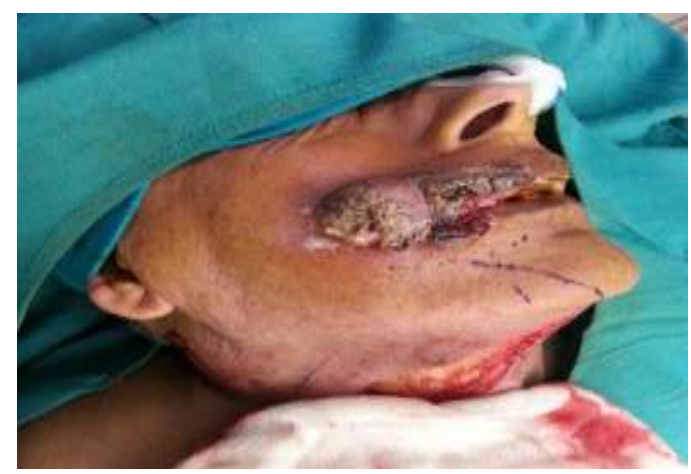

Figure Ia - The primary lesion

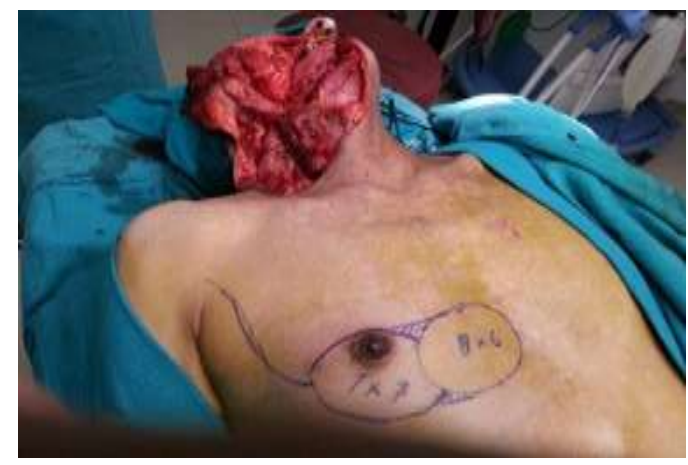

Figure I $\boldsymbol{b}$ - The flap size and design

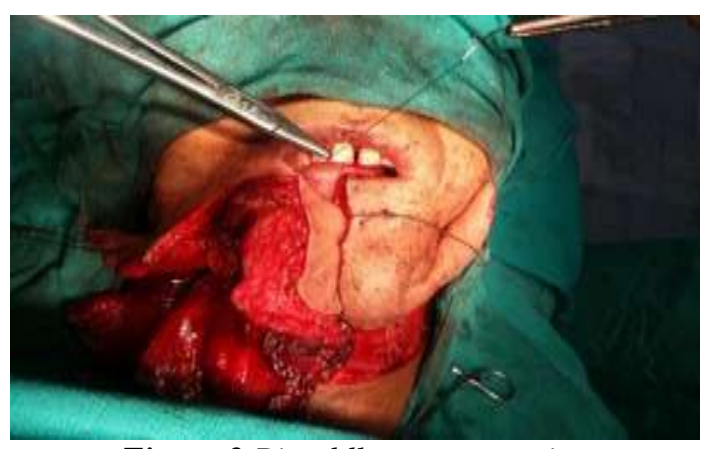

Figure 2 Bipaddle reconstruction 


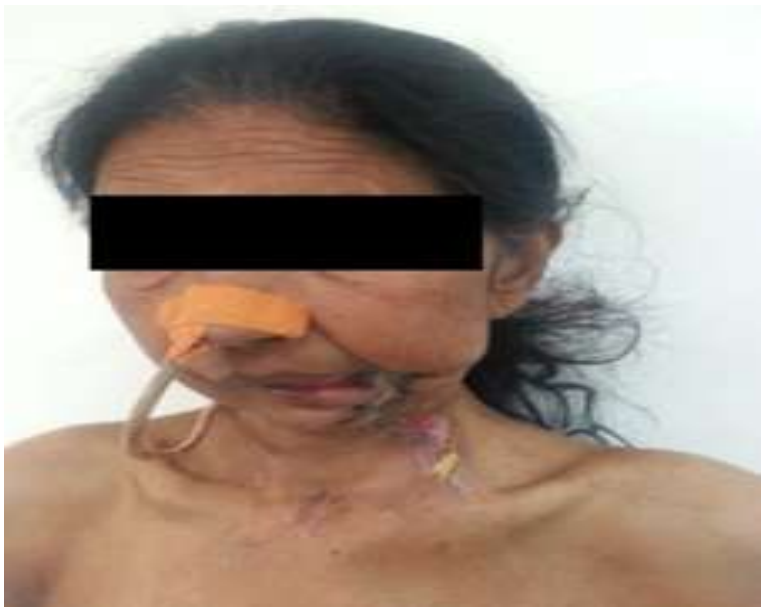

Figure 3(a) Partial flap necrosis

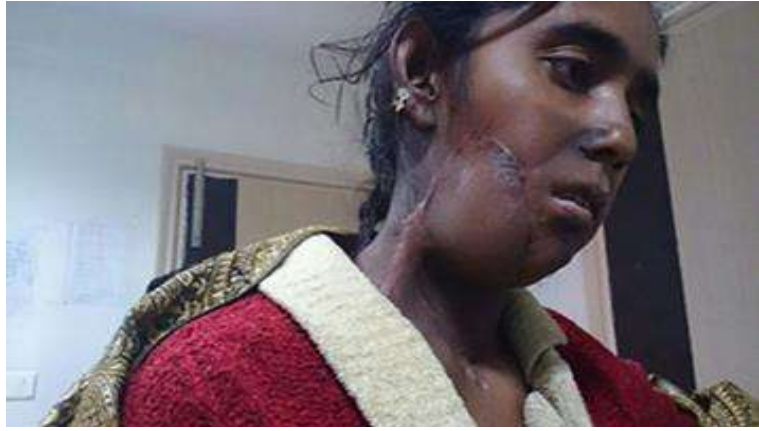

Figure 3(b) Healthy flap post Radiation

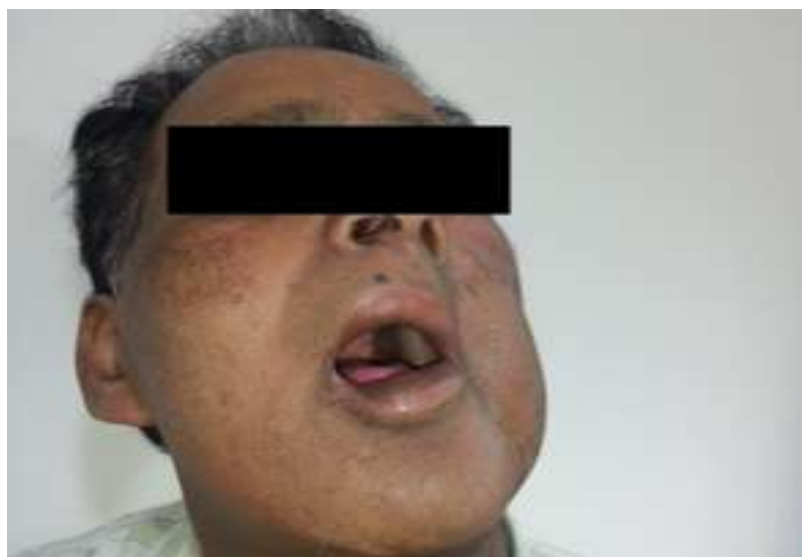

Figure 4(a) Inner flap

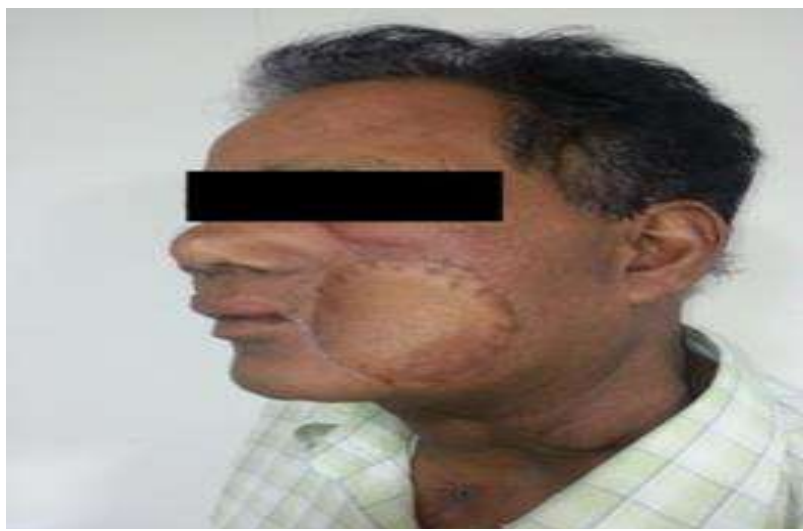

Figure 4(b) Outer flap 